\title{
Effect of Stirring on Crystal Morphologies and on Macro-Segregation
}

\author{
Toshio Fujimura $^{1} \&$ J. K. Brimacombe ${ }^{2}$ \\ ${ }^{1}$ Rinko corporation, Tokyo, Japan \\ ${ }^{2}$ Decedent, British Columbia University, Vancouver, Canada \\ Correspondence: Toshio Fujimura, Rinko corporation, Tokyo, Japan. E-mail: tomohio1000@gmail.com
}

Received: June 8, 2017

Accepted: June 20, 2017

Online Published: June 30, 2018

doi:10.5539/jmsr.v7n3p37

URL: https://doi.org/10.5539/jmsr.v7n3p37

\begin{abstract}
To minimize the macro-segregation in continuously cast steel slabs, the effects of the stirring on the macrosegregation were studied. Industrial findings by the metallographic observations of the steel slabs showed macrosegregation was improved by the refinements of crystals. It was also found that the stirring at low fraction solid refined crystals. The unsolidified liquid core of the continuously cast slab with the optimum stirring was well packed with the refined crystals whereas it was not with coarse equiaxed crystals. The analogue study with experiments of $\mathrm{Pb}-\mathrm{Sn}$ alloy showed, similarly as with steel slabs, the stirring at low solid fraction refined crystals. Also, the artificially created cavity in a mush was well packed with the refined, globular, crystals whereas it was not with the coarse dendritic crystals. Thus, it is considered the stirring at the low solid fraction is advantageous to refine crystals and to improve macro-segregation.
\end{abstract}

Keywords: continuous casting, segregation, stirring, crystals, morphology

\section{Introduction}

The goal of continuously casting slabs with homogeneous composition is difficult to achieve owing to the strong tendency for elements such as phosphorous, sulfur and manganese to segregate. The segregation may appear on the "micro" scale between dendrite arms or on the larger "macro" or semimacro" scale. Macro and Semimacrosegregation are particularly undesirable in slabs for plate application because they may give rise to welding cracks, ultrasonic-inspection defects, hydrogen-induced cracks (Saeki et al., 1985). Ohashi et al. (1986) reported the precipitated $\mathrm{MnS}$ inclusion deteriorated both the ductile fracture and brittle fracture of the steel plate. It was also found that manganese and phosphorous in the segregated region of the steel plate decreased the nil-ductility transition temperature in notch tensile tests due to the transformation to the multensite-bainite duplex structure (Yamanaka, 1980). The hydrogen induced cracks are also induced by the segregations of manganese and phosphorous (Yamanaka, 1980). The macro- or semimacro- segregations appear at the centerline or as spots distributed in the central region in continuously cast slabs. Macro-segregation is caused by liquid movement in the semi-solid mush during the sinolidification process; in the interior of slabs it is influenced by the morphology and packing of crystals, and electromagnetic stirring below the mould (Kitaoka et al., 1983; Fujimura, Takeuchi, \& Brimacombe, 1985).

The objectives of this study are to elucidate the influence of the crystal morphology on macro segregation based on the industrial findings and the analogue study with $\mathrm{Pb}-\mathrm{Sn}$ alloy.

\section{Macro-Segregation in the Interior of Slabs}

Macro-segregation in the interior continuously cast slabs is influenced by the shape pf crystals freely moving in the liquid pool and by the closeness of packing of crystals as they settle under the influence of gravity to the bottom of the sump. Coarse dendritic crystals, for example, do not pack closely, as compared to fine "globular" (more equiaxed) crystals, leaving relatively large pockets of liquid in which elements such as manganese, phosphorous and sulphur may segregate during solidification (Fujimura, Takeuchi, \& Brimacombe, 1985). Bulging of the slabs near the point of final solidification also is a major factor in the formation of centerline segregation as interdendritic liquid is drawn into the void created by the bulging action.

The influence of stirring on the refinement of crystal shape and macro-segregation were investigated with aid of a $\mathrm{Pb}-10 \%$ Sn alloy analogue of steel (Fujimura, Takeuchi, \& Brimacombe, 1985).

\subsection{Industrial Findings}

The specifications of the casting machine and the conditions under which the industrial trials were conducted are presented in Table 1. It may be noted that stirrers were located at two positions beneath the mould, 5.4 and $10.4 \mathrm{~m}$ below the meniscus respectively. In the test, the casting speed was varied so that the thickness of the solid shell, 
or fraction of unsolidified core remaining, change at the stirrer position. The liquid core fraction, fc, defined as the ratio of the thickness of the unsolidified zone between the upper and bottom side of white bands, caused by the liquid flow by EMS, relative to the slab thickness, could be determined directly by measuring the position of the white bands in transverse sections of fully solidified slabs (Kitaoka et al., 1983). The effect of liquid core fraction, $\mathrm{f}_{\mathrm{C}}$ at the No.2 stirrer, on centerline segregation was shown in Figure 1 (Kitaoka et al., 1983; Fujimura, Takeuchi, \& Brimacombe, 1985). Thus it is seen that centerline segregation, expressed as an index (I.C.S. $=$ area at the centerline occupied by segregated solutes/overall length of centerline length), is nearly the same with either both No.1 and No.2 stirrers or solely No.2 stirrer. This suggest that the No.1 stirrer is not as effective in changing the macro-segregation as the No.2 stirrer. It also is observed that the centerline segregation is a minimum when the liquid core fraction, $\mathrm{f}_{\mathrm{C}}$ is about 0.2 . It is considered, hence, that the stirring at $\mathrm{fc}=0.2$ which corresponds to low fraction solid in liquid core is effective to refine crystals, whereas the stirring at $\mathrm{fc}=0.07$ which corresponds to the high solid fraction in liquid core is not.

To improve the susceptibility to Hydrogen Induced Cracking (HIC) in the steel plates for line pipe use, the solutes distributions in the transverse section (samples of $4 \times 4 \mathrm{~cm}^{2}$, were taken from the central region of continuously cast slabs) were investigated. The extent of the segregations of manganese and phosphorous in the samples were measured by an EPMA Macroanalyzer with the $100 \mu \mathrm{m}$ diameter beam. The points of measurements to cover $4 \times 4 \mathrm{~cm}^{2}$ section was $64 \times 10^{4}$. The maximum concentrations relative to those of bulk liquid decreased with the decrease of the sizes of semimacro-segregation spots, as shown in Figure 2. It is seen that stirring at $\mathrm{fc}=0.2$ is advantageous to decrease the sizes of spots which results the decrease of the maximum concentration ratio of manganese and phosphorous in semimacro-segregation spots. Figure 3 shows the influence of the the liquid core ration $\mathrm{fc}$ on the sizes of the spots, semimacro-segregations distributed in the central region of continuously cast steel slabs. It is seen that the number of the spots, semimacro-segregations with the diameter more than $1 \times 10^{-1} \mathrm{~cm}$ decreases with the decrease of fc.

Thus, it is considered that the stirring at $\mathrm{fc}=0.2$ is more effective than that at $\mathrm{fc}=0.3 \mathrm{or} f \mathrm{c}=0.37$ to refine crystals and reduce the maximum concentrations of manganese and phosphorous in the segregated spots. It is noted that this results are consistent with the results of I.C.S. in the range of the higher fc more than 0.2 (Figure 1).

Thus, hence, it is considered that the refinement of crystals to obtain closer packing of crystals and smaller semimacro-segregation spots between crystals. It may be noted that the susceptibility to HIC can be improved by decreasing the phosphorous concentration of bulk liquid as to the minimum level of $0.005 \%$ (Haida et al., 1984) which may not be always available in the general mass production process. Thus, the efforts to minimize the macro- or semimacro- segregation in continuously cast slabs should be necessary.

A detailed metallographic study (Kitaoka et al., 1983; Fujimura, Takeuchi, \& Brimacombe, 1985) was made of changes to crystal morphology in the center region of slabs cast with EMS as shown in Figure 4. Both crystals in $\mathrm{B}\left(\mathrm{f}_{\mathrm{C}}=0.2\right)$ and $\mathrm{C}\left(\mathrm{f}_{\mathrm{C}}=0.37\right)$ are refined and more globular than those in $\mathrm{A}\left(\mathrm{f}_{\mathrm{C}}=0.07\right)$. This revealed that, depending on the casting speed, No.2 EMS had the effect of changing crystal morphology from coarse dendritic to a finer globular shape. The influence of the casting speed on the thickness of the refined crystals in the core of the slab and the positions of the zone of refined crystals are shown in Figure 5. Thus, the strongest influence of stirring (No.2 EMS) on crystal refinement was found at casting speed $1 \mathrm{~m} / \mathrm{min}\left(\mathrm{f}_{\mathrm{C}}=0.2\right)$. Below $0.9 \mathrm{~m} / \mathrm{min}$ (typically $0.7 \mathrm{~m} / \mathrm{min}, \mathrm{fc}=0.07$ ), there is virtually no refinement of crystal morphology by EMS. The refined crystal zone is seen to be displaced toward the lower side of the slab due to descending crystals settling into the curved liquid cavity. As a results, a vertical symmetry on crystal structure at $1.0 \mathrm{~m} / \mathrm{min}(\mathrm{fc}=0.2)$ is lost at the higher casting speed (e.g. at $1.3 \mathrm{~m} / \mathrm{min}(\mathrm{fc}=0.37)$ ), so that the upper side of liquid core is not sufficiently filled with refined crystals as compared to that at $1.0 \mathrm{~m} / \mathrm{min}(\mathrm{fc}=0.2)$. Thus, it is considered that the stirring at $\mathrm{fc}=0.2$ which corresponds to low fraction solid in liquid core is effective to refine crystals and desirable to obtain a symmetry on crystal structure.

These findings are summarized as follows:

(1) The electromagnetic stirring EMS at $\mathrm{fc}=0.2$ minimize the Index of Centerline segregation, I.C.S. (Figure 1).

(2) The refinements of crystals is obtained when fc is larger than 0.2 and is not when fc is smaller than 0.2 (e.g. $\mathrm{fc}=0.07$ ), so that the stirring at $\mathrm{fc} \geq 0.2$ is essential to refine crystals (Figure 4and 5).

(3) The sizes of macro- or semimacro- segregation spots decrease with the decrease of fc (Figure 2).

(4) (2) and (3) suggest that the extents of manganese and phosphorous of macro- or semimacro segregation spots are minimized by the stirring at $\mathrm{fc}=0.2$.

(5) (4) and (1) are consistent each other. 
Table1. Principal specifications of the caster and test conditions

\begin{tabular}{lll}
\hline & Item & Specification \\
\hline Machine specification & Machine type & \multicolumn{1}{l}{$\begin{array}{l}\text { Vertica-Progressive bending-progressive } \\
\text { unbending }\end{array}$} \\
& Length of vertical supporting & $3000 \mathrm{~mm}$ \\
& Metallurigacal length & $36.5 \mathrm{~m}$ \\
Casting conditions & Slab size & $230 \times 1300 \mathrm{~mm}$ \\
& Casting velocity & $0.7-1.3 \mathrm{~m} / \mathrm{min}$ \\
& Superheat & $18-40^{\circ} \mathrm{C}$ \\
& Chemical composition of the cast steel & $0.12-0.18 \% \mathrm{C}, 0.014-0.024 \% \mathrm{Si}$, \\
& & $0.80 \% \mathrm{Mn}, 0.009-0.023 \% \mathrm{P}$, \\
& & $0.007-$ \\
& & $0.016 \% \mathrm{~S}$ \\
& Stirrer type & Linear mortor type \\
& Stirring direction & Horizontal \\
& Frequency & $0.3-3.0 \mathrm{~Hz}$ \\
& Distance from the meniscus & No.1 EMS $5.4 \mathrm{~m}$ \\
& & No.2 EMS $10.4 \mathrm{~m}$ \\
\hline
\end{tabular}

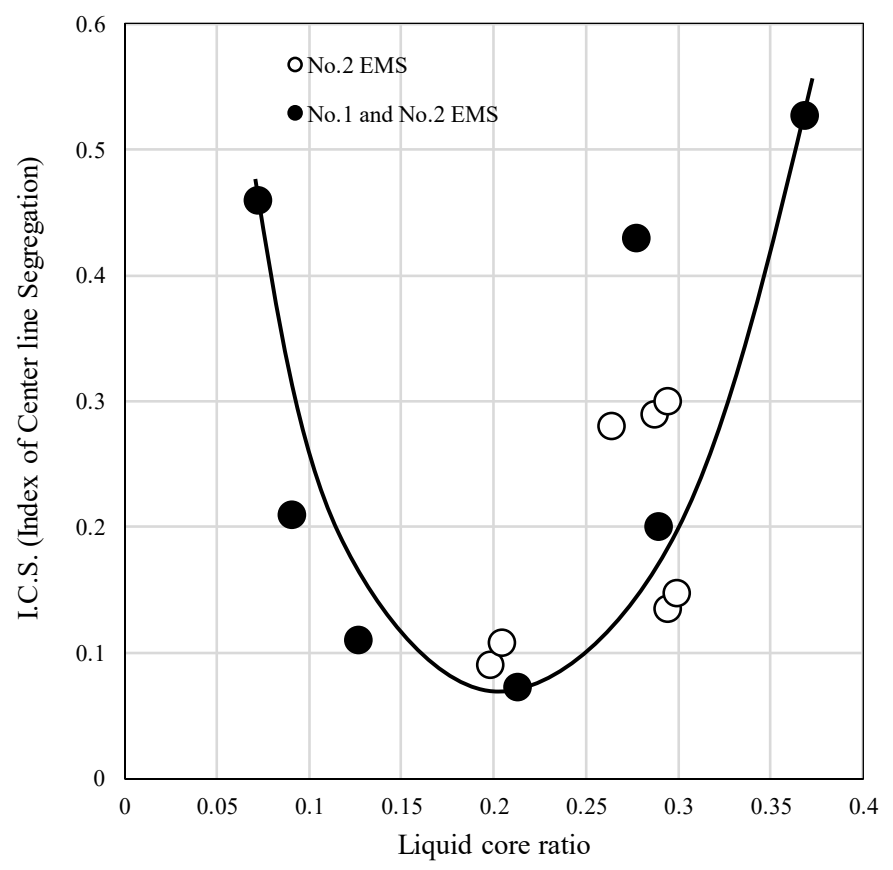

Figure 1. Effect of the liquid core ratio of the slabs where liqiuid core was stirred by No.2 EMS (Kitaoka et al., 1983; Fujimura, Takeuchi, \& Brimacombe, 1985) 

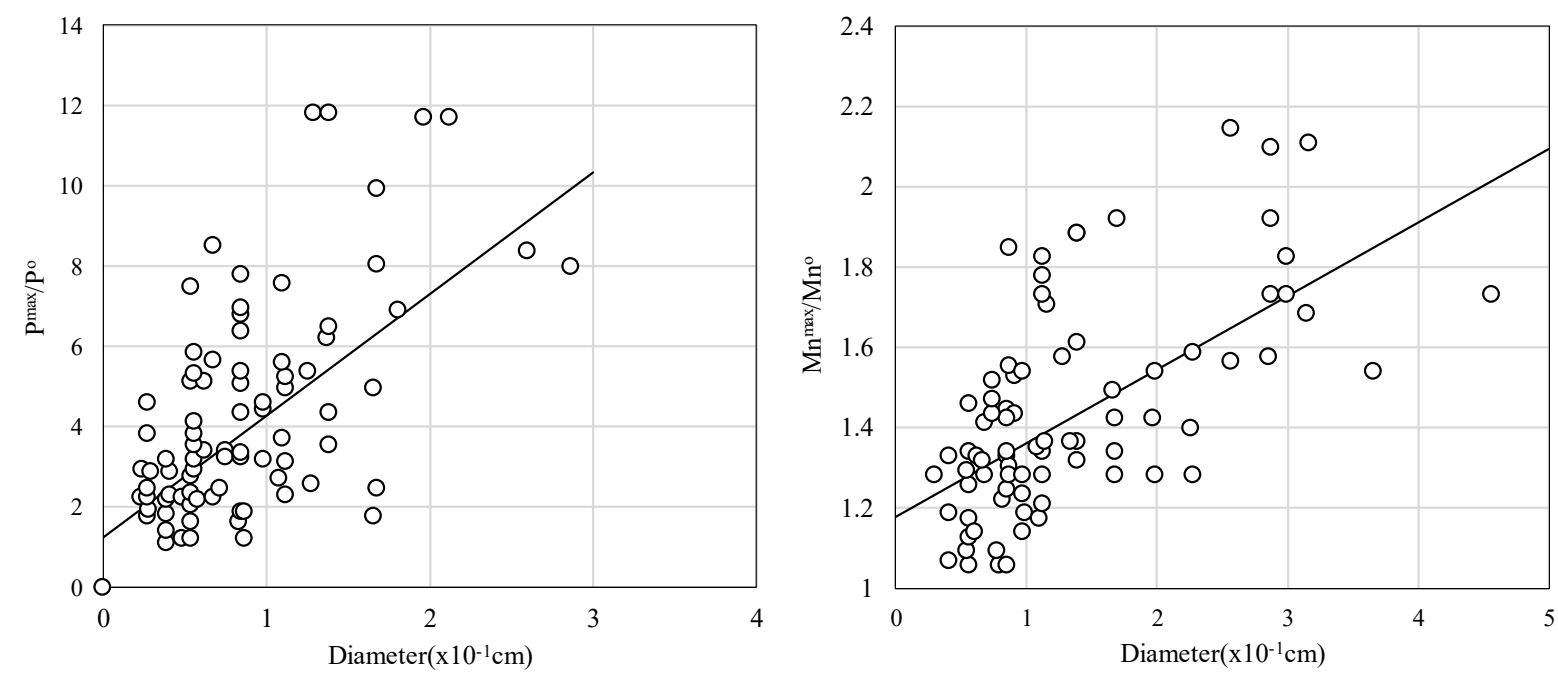

Figure 2. Relations between the extents of maximum concentration of solutes and diameters of the semimacro segregation. Measure by the EPMA Macroanalyzer with $100 \mu \mathrm{m}$ beam

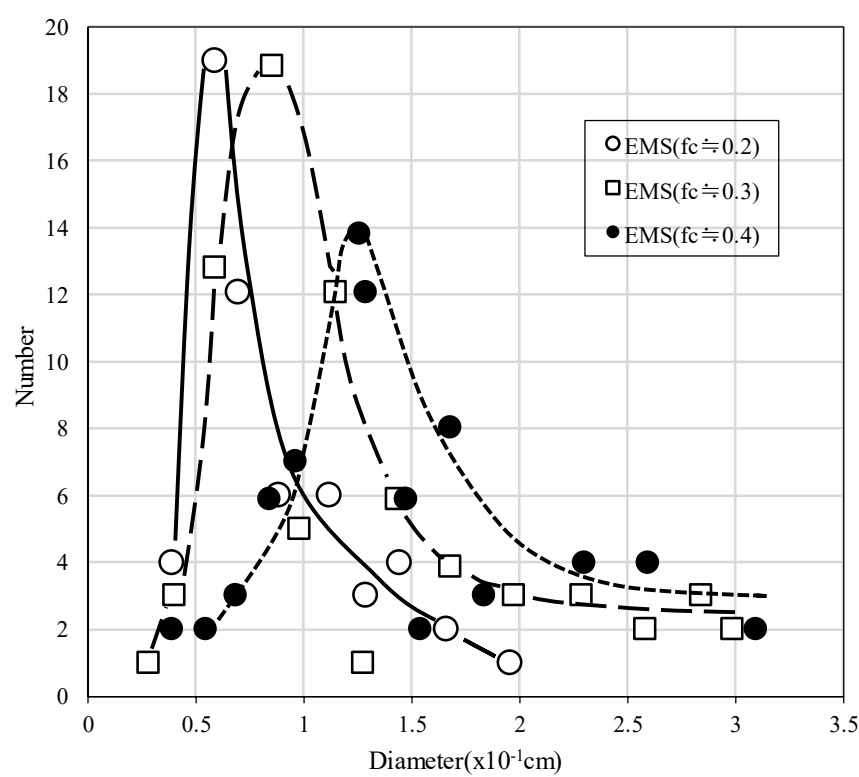

Figure 3. Effect of the liquid core ratio of the slabs where liqiuid core was stirred by No.2 EMS on the sizes of semi-macro- segregations (spots distributed in central region of continuously cast slabs) 


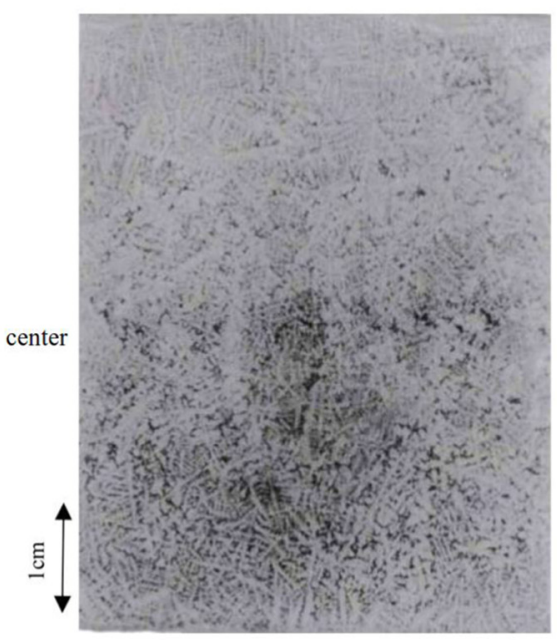

$\mathrm{A}(\mathrm{fc}=0.07)$

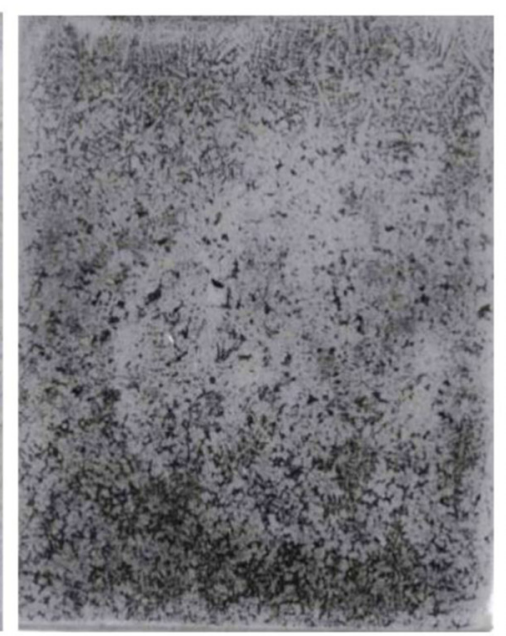

$\mathrm{B}(\mathrm{fc}=0.2)$

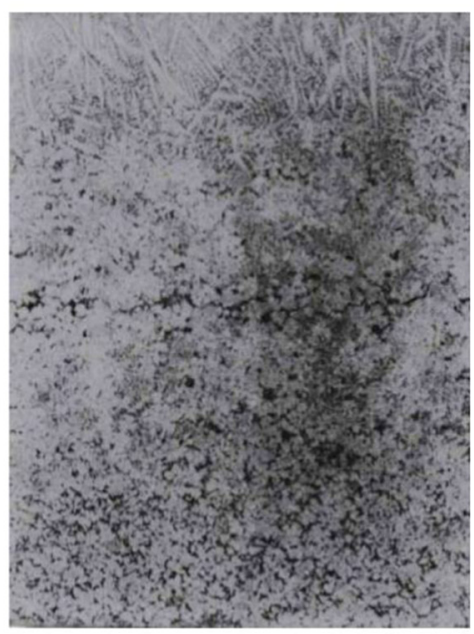

$\mathrm{C}(\mathrm{fc}=0.37)$

Figure 4. Crystal morphologies in the transverse sections of the continuously cast slab stirred by EMS at the different liquid core ratio (Chemical composition: $0.12-0.18 \% \mathrm{C}, 0.014-0.024 \% \mathrm{Si}, 0.55-0.80 \% \mathrm{Mn}, 0.009$ -

$0.023 \% \mathrm{P}, 0.007-0.016 \% \mathrm{~S}$, Casting speed $0.7-1.3 \mathrm{~m} / \mathrm{min}$ )

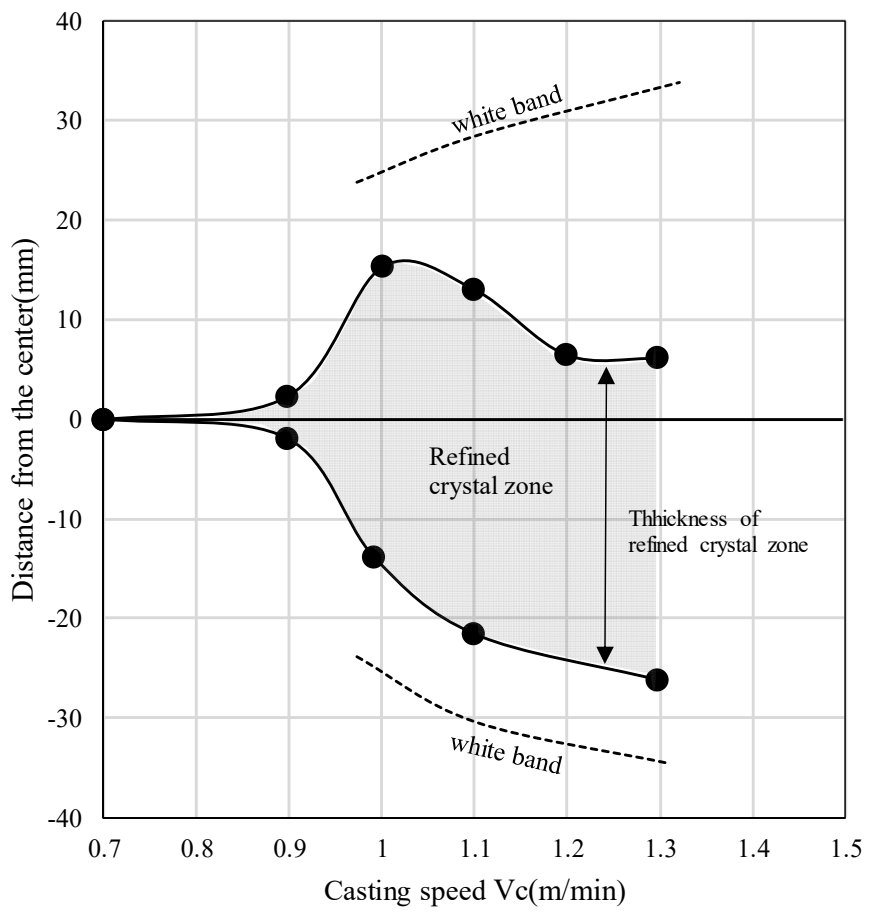

Figure 5. Influence of the casting velocity on the positions of the central zone of refined crystal zone and white bands induced by No.2 EMS (Fujimura, Takeuchi, \& Brimacombe, 1985)

\subsection{Analogue Study with Mechanical Stirring}

The effect of mechanical stirring on crystal morphology and macro-segregation was studied in the laboratory using the rotary furnace shown in Figure 6 (Fujimura, Takeuchi, \& Brimacombe, 1985). The furnace was resistively heated and was rotated at a speed of 125 r.p.m. A mould shown in Figure 7. was located inside the furnace. The mould was constructed of stainless steel, coated with carbon paste and was capable of disassembly to release the solidified ingot of $\mathrm{Pb}-10 \% \mathrm{Sn}$ used as the metal analogue. The Phase diagram of $\mathrm{Pb}$-Sn binary alloy (Gouttebroze, Fachinotti, Bellet, \& Combeau, 2005) is shown in Figure 8. The bottom of the mould also was fitted with a plunger which could be withdrawn partially prior to complete solidification of the ingot to simulate the action of slab bulging or solidification shrinkage. 
In the experiments, molten alloy was cooled at $2^{\circ} \mathrm{C} / \mathrm{min}$ and below $350^{\circ} \mathrm{C}$ tumbled to the desired test temperature in solid -liquid region. The cooling rate below the liquidus temperature $\left(300^{\circ} \mathrm{C}\right)$ was $0.5^{\circ} \mathrm{C} / \mathrm{min}$. The temperature then was held constant and tumbling was continued for various times. Finally, tumbling was stopped for 180 s to permit the crystals to settle and thereafter the plunger rod was pulled downward to create an artificial cavity in the sedimented crystal zone. After another 180s the mould was water quenched; The Pb-Sn ingot subsequently was sectioned axially, polished, etched and examined with respect to crystal morphology. Typical examples are shown in Figure 9: Both of sample $\mathrm{E}$ and $\mathrm{K}$ were cooled stationary, but $\mathrm{K}$ was tumbled from $294^{\circ} \mathrm{C}$ to $289^{\circ} \mathrm{C}(\mathrm{fs}=0.4-0.7)$ and sample D were continuously tumbled from $300^{\circ} \mathrm{C}(\mathrm{fs}=0)$ to $294^{\circ} \mathrm{C}(\mathrm{fs}=0.4)$.

It was found that crystal refinement was achieved by mechanical stirring (tumbling) when the fraction solid was less than 0.4(Sampke D in Figure 9). It was also found that the dendritic crystals precipitated in the low faction solid (fs is 0 to 0.4 ) are hardly refined by the mechanical stirring (Sample K in Figure 9). This can be seen also in Figure 10. The fraction of solid was estimated by the lever rule because the liquid and solid were fully mixed by tumbling under slow cooling rate. It may be noted, in the range of low solid fraction, those estimated with lever rule were roughly consistent with the estimates by Scheil's equation (the partition ratio of tin, $\mathrm{k}_{\mathrm{Sn}}=0.55$, can be used as the averaged the equilibrium partition ratio of $\mathrm{Pb}-10 \% \mathrm{Sn}$ alloy). Thus, it is considered that the stirring at low solid fraction ( $\mathrm{fs}<0.4$ ) is essential to refine crystals.

With respect to packing/macro-segregation, the fine, globular shape, crystals generated by tumbling were found to occupy the void created by the withdrawn plunger (Sample D and G). However unrefined coarse dendritic crystals did not behave similarly but remained stationary and only inter-dendritic liquid filled the cavity to create a pocket of macro-segregation (Sample E and K) as shown in Figure 10.

Clearly the fine globular crystals are desirable both from the standpoint of packing and minimization of macrosegregation. It may be noted that when the artificial cavity was created with solid fraction greater than 0.75 neither crystals (of any shape) nor inter-dendritic liquid moved to fill it. This findings agrees well with results reported for steel by Takahashi, Kudoh, and Nagai (1982).
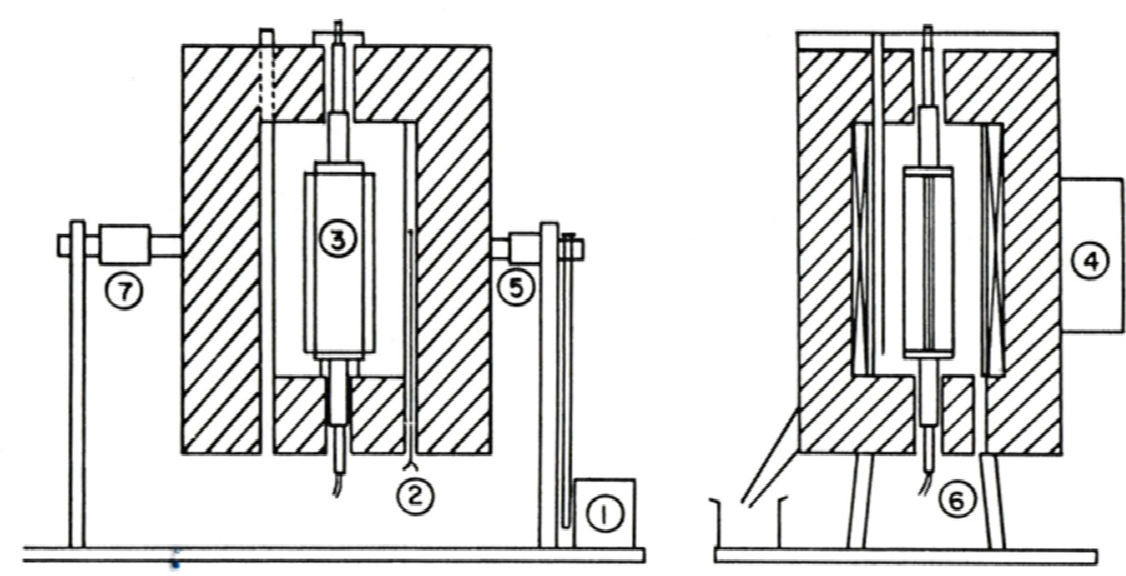

Figure 6. Scematic diagram of rotary furnace: (1) motor (2)chromel-alumerl thermocouple (3) mould (4) ice cold junction (5) water inlet (6) water outlet (7) slip ring for thermocouple and power supply (Fujimura, Takeuchi, \& Brimacombe, 1985) 


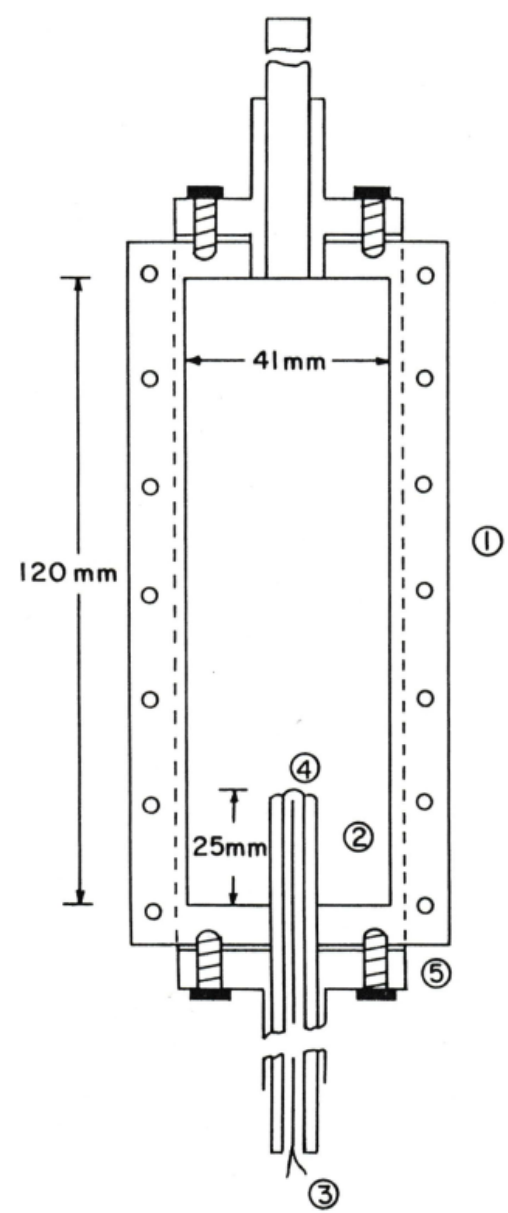

Figure 7. Schematic diagram of the mould used in the mechanical stirring(tumbing) experiments. (1) stainless steel mould (2)cylindrical plunger (3)chromel-alumel thermocouple (4) 4mm glass tube (5) aluminum seal olate (Fujimura, Takeuchi, \& Brimacombe, 1985)

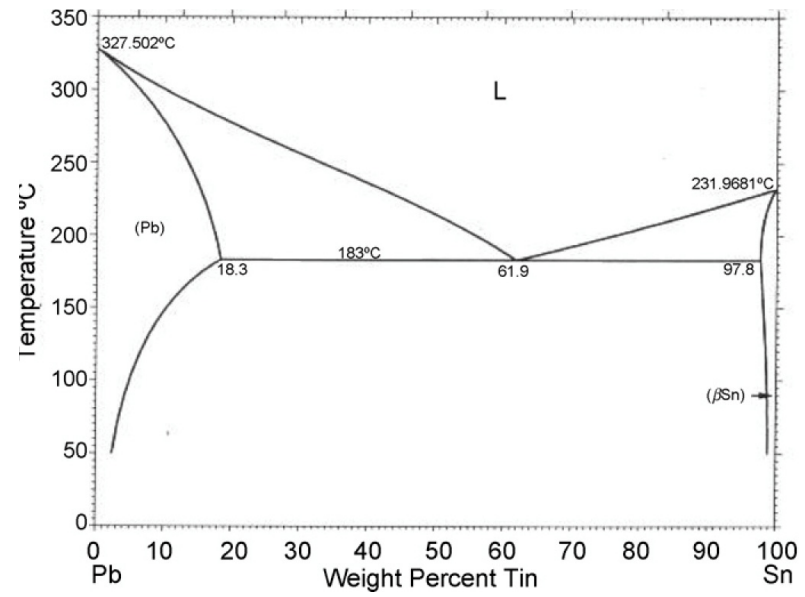

Figure 8. Phase daigarm of Pb-Sn binary alloy (Gouttebroze, Fachinotti, Bellet, \& Combeau, 2005) 


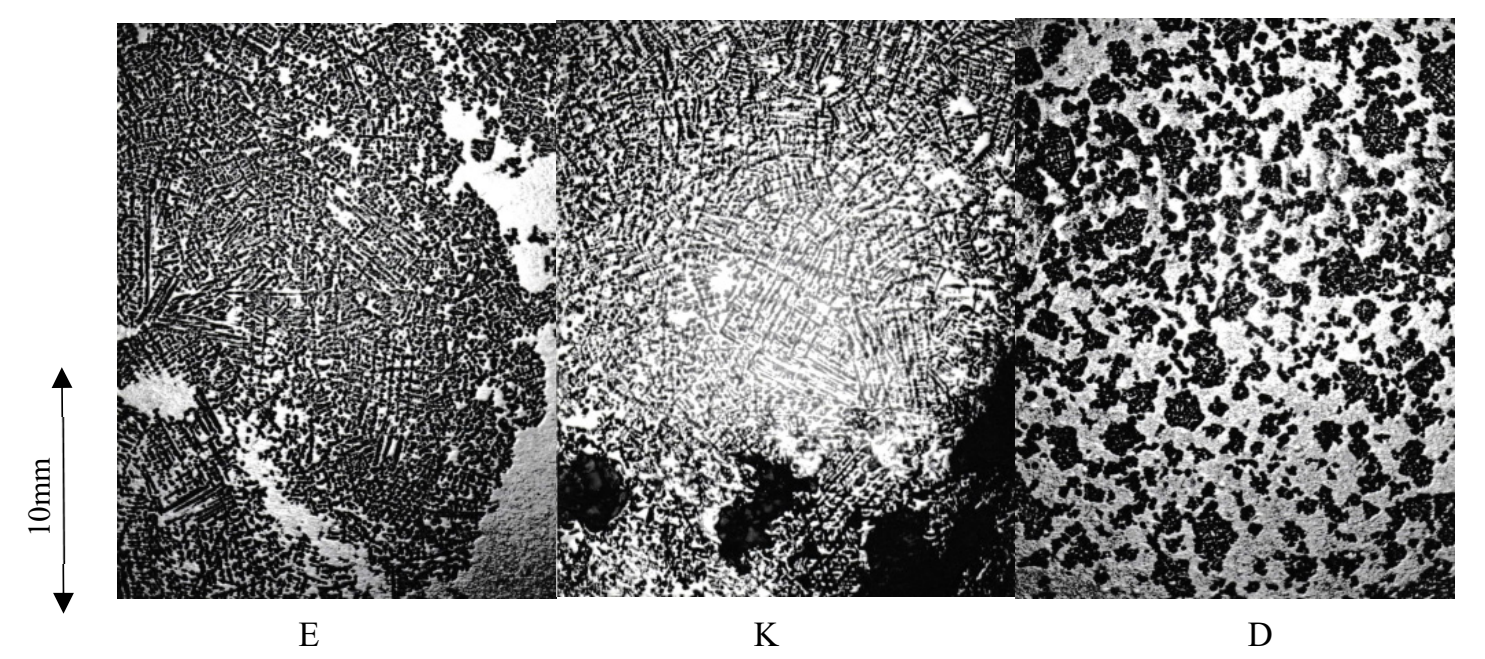

\begin{tabular}{|c|c|c|c|c|}
\hline \multirow{2}{*}{} & \multicolumn{2}{|c|}{ Tumbled } & Tumbling time $(\mathrm{min})$ & Quenched temperature $\left({ }^{\circ} \mathrm{C}\right)$ \\
\cline { 2 - 5 } & $0<\mathrm{fs}<0.4$ & $0.4<\mathrm{fs}$ & & \\
\hline $\mathrm{E}$ & - & - & non & $294(\mathrm{fs}=0.4)$ \\
\hline K & - & 0 & 20 & $289(\mathrm{fs}=0.7)$ \\
\hline$D$ & 0 & - & 20 & $294(\mathrm{fs}=0.4)$ \\
\hline
\end{tabular}

Figure 9. Refinement of crystals from the dendritic crystals to the globular crystals by mechanical stirring (tumbling the mould)

Note: The refined globular crystals were found in sample D (tumbled $0<\mathrm{fs}<0.4$ ). Dendritic equiaxed crystals in sample K were hardly refined with the tumbling at high fraction solid (fs $>0.4$ ).

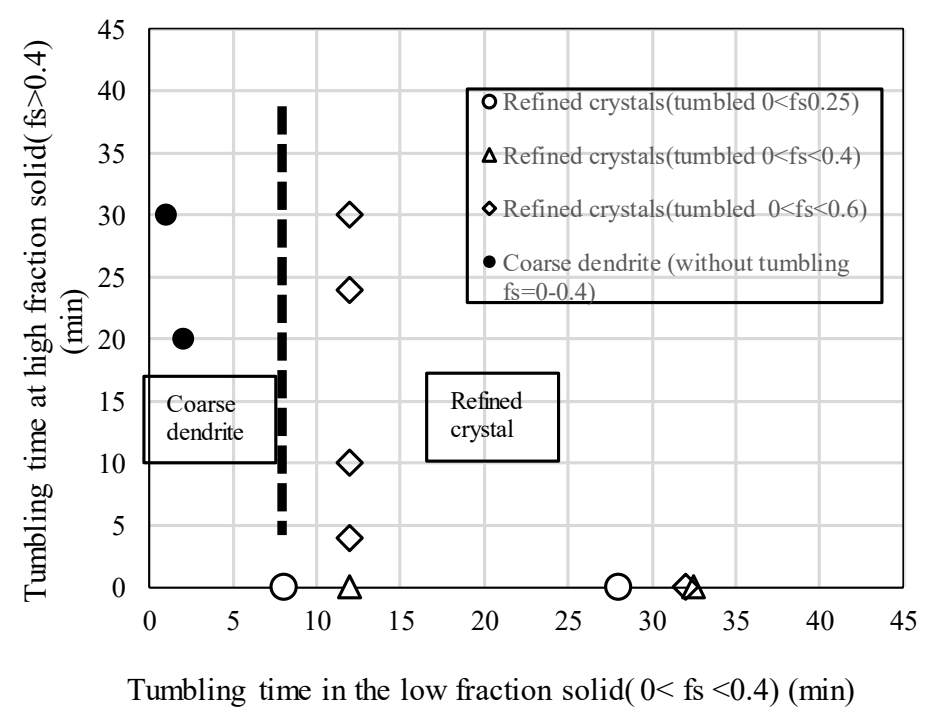

Figure 10. Effect of the tumbling on crystal morophologies of $\mathrm{Pb}-10 \% \mathrm{Sn}$ alloy 


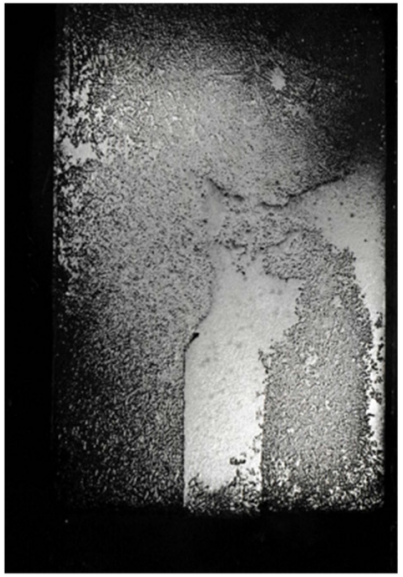

Sample E

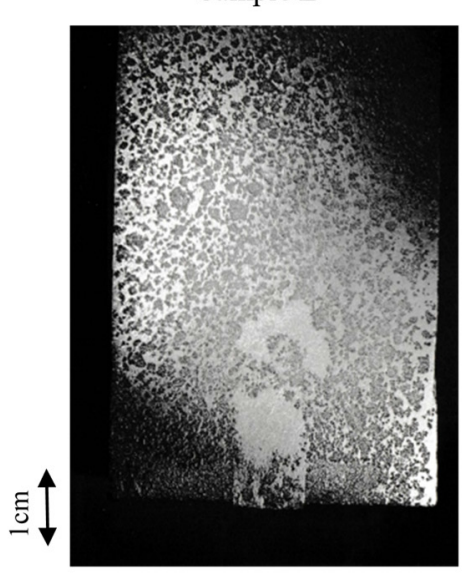

Sample D

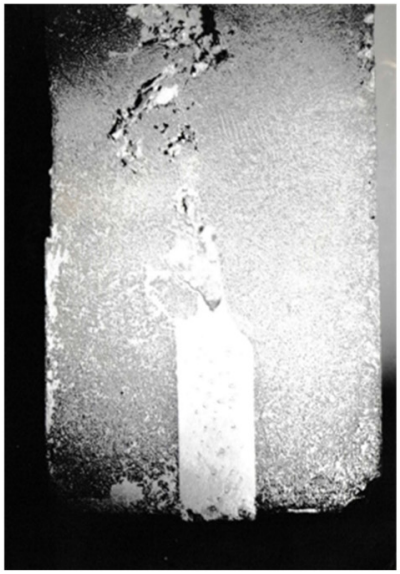

Sample K

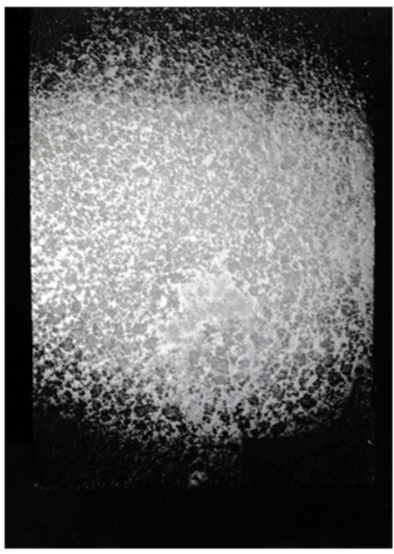

Sample G

\begin{tabular}{|c|c|c|c|c|}
\hline & \multicolumn{2}{|c|}{ Tumbled } & Tumbling time $(\mathrm{min})$ & $\begin{array}{c}\text { Temperature of the creation } \\
\text { of a cavity by pulling down a } \\
\text { plunger }\left({ }^{\circ} \mathrm{C}\right)\end{array}$ \\
\cline { 2 - 5 } & $0<\mathrm{fs}<0.4$ & $0.4<\mathrm{fs}$ & & $294(\mathrm{fs}=0.4)$ \\
\hline E & - & - & non & $289(\mathrm{fs}=0.7)$ \\
\hline K & - & $\bigcirc$ & 20 & $294(\mathrm{fs}=0.4)$ \\
\hline D & & - & 20 & $292(\mathrm{fs}=0.5)$ \\
\hline G & & & 20 & \\
\hline
\end{tabular}

Figure 11. Effects of crystal morphologies on packing the void created by the withdrawn plunger Note: a mould was kept stationary at the quenche temperature for 180 s before creating the cavity.

\section{Discussion}

Laboratory experiments with $\mathrm{Pb}-\mathrm{Sn}$ alloy have been conducted to explain the effect of EMS on the refinement of internal structure in continuously cast slabs (Fujimura, Takeuchi, \& Brimacombe, 1985). These analogue study has shown that stirring at low fraction solid is essential to refine crystals. Also unrefined coarse, dendritic crystals do not move easily to fill voids created by bulging or solidification shrinkage; instead inter-dendritic liquid may fill the cavities and create zones of macro-segregation.

The numerical heat analysis on the continuous casting was performed to compare the metallographic findings of the continuously cast slabs with this analogue study. The heat analysis focusing on the interior temperature in the steel slab, however, is not easy, as compared to that on the surface temperature analysis, because of the lack of the measured temperature of the interior of slabs in the real process. Moreover, the heat generation due to solidification in a mushy zone is not sufficiently relevant and the reported formulae of the solidus temperature have not been confirmed with the reliable measurements. For example, significant discrepancies exist between the thermoanalytical measurements of the small specimen and the values obtained from the reported formulae (up to $40 \mathrm{~K}$ ) or the thermodynamic caluculations (up to 50k) (Gryc et al., 2013). To overcome these issues, Fujimura and Brimacombe (1986) and Fujimura, Takeshita, and Suzuki (2018) obtained the approximate analytical solutions of 
the heat- and solute transfer equations assuming the linear heat generation in a mushy zone with respect to temperature. It was shown the solutions for continuous casting of the steel were consistent with Neuman's solution in the low carbon concentration range and the conventional numerical heat analysis, such as the equivalent specific heat method. Based on these studies, the numerical heat analysis of the continuously cast slabs by the equivalent specific heat analysis with the upwind finite-deference method was demonstrated assuming a linear heat generation in a mushy zone with respect to temperature. A symmetric condition was used at the center of a slab. The surface temperature at the early stage and both at the middle and final stage was calibrated with the reliable analysis based on the measurements by Meng and Thomas (2003) and the typical process data of the caster, respectively. The physical properties, the liquidus temperature (Kawawa, 1977) and the solidus temperature (Hirai, Kanamaru, Mori, 1977) used in the analysis are listed in Table2. It is noted that the influence of the stirring by EMS on the solidification was neglected in the heat analysis assuming that the mixing of liquid occurs only in the limited region near the EMS position.

The result of the numerical heat analysis for the case of $1.0 \mathrm{~m} / \mathrm{min}$ (liquid core ratio $\mathrm{fc}=0.2$ ) was shown in Figure 11. The position of the white band due to No.2 EMS measured directly in the transverse section of the fully solidified slab was also shown in Figure 11. The solid fraction fs at the position of white band roughly corresponds to that of 0.1 predicted by the numerical heat analysis. The exact fraction solid of the white band, unfortunately, is not sufficiently relevant even though many of the investigations focusing on white band (Takahashi, Kudoh, \& Nagai, 1982; Ujiie et al., 1981) were conducted. However, it is considered that white band could be formed in the range from fs $=0$ to $\mathrm{fs} \fallingdotseq 0.7$ ( at fs $>0.67$, the liquid in a mushy zone can not freely move) (Takahashi, Kudoh, \& Nagai, 1982). Thus, it is considered, at least, that the result of heat analysis is not unreasonable. Table 3 shows the summary of the results of both the continuous casting of steel slabs and the analogue study by Pb-Sn alloy on the refinement of crystals. The estimated fraction solid fs defined as an averaged fraction solid in the liquid core within the white bands was 0.15 for case $\mathrm{A}(\mathrm{fc}=0.07)$ where only coarse dendritic crystals were observed. In contrast to $\mathrm{A}$, the estimated $\overline{\mathrm{fs}}$ of $\mathrm{B}(\mathrm{fc}=0.2)$ and $\mathrm{C}(\mathrm{fc}=0.37)$ were 0.02 and 0.03 , respectively, where the refined crystals were observed in a liquid core. These results suggest that the refinement of crystals is obtained by EMS where fraction solid is low but is not obtained at the high solid fraction solid. It should be noted that the liquid core of A was considered to be stirred after coarse dendritic crystals developed, so that these coarse crystals were not refined by the stirring. These findings are, basically, well consistent with the results of the analogue study of $\mathrm{Pb}-$ Sn alloy (Table 3).

Accordingly, it is considered, thus, the refinement of crystal, which is achieved by the stirring at low solid fraction, is advantageous to minimize macro-segregation by the close packing of refined crystals in the unsolidified liquid core of the continuously cast slabs.

Table 2. Physical properties used in the thermal analysis

\begin{tabular}{cccc}
\hline & \multicolumn{2}{c}{ Property } & Value \\
\hline Solid & $\rho_{1}$ & Density & $7.7 \times 10^{3} \mathrm{Kg} / \mathrm{m}^{3}$ \\
zone & $\mathrm{C}_{\mathrm{p} 1}$ & Specific heat & $0.77 \mathrm{~kJ} / \mathrm{kgK}$ \\
& $\mathrm{K}_{1}$ & Thermal conductivity & $30.6 \mathrm{~W} / \mathrm{mK}$ \\
Solid and Liquid & $\mathrm{L}$ & Heat of fusion & $276 \mathrm{~kJ} / \mathrm{kg}$ \\
coexsiting & $\rho_{2}$ & Density & $7.5 \times 10^{3} \mathrm{Kg} / \mathrm{m}^{3}$ \\
zone & $\mathrm{C}_{\mathrm{p} 2}$ & Specific heat & $0.77 \mathrm{~kJ} / \mathrm{kgK}$ \\
Liquid & $\mathrm{K}_{2}$ & Thermal conductivity & $31.8 \mathrm{~W} / \mathrm{mK}$ \\
zone & $\rho_{3}$ & Density & $7.4 \times 10^{3} \mathrm{Kg} / \mathrm{m}^{3}$ \\
& $\mathrm{C}_{\mathrm{p} 3}$ & Specific heat & $0.77 \mathrm{~kJ} / \mathrm{kgK}$ \\
\multicolumn{2}{c}{ Liquidus temperature (Kawawa, 1977) } & $35.0 \mathrm{~W} / \mathrm{mK}$ \\
Solidus temperature (Hirai, Kanamaru \& Mori, 1977) & $1793 \mathrm{~K}$ \\
Steel composition & \multicolumn{2}{c}{$0.15 \% \mathrm{C}, 0.65 \% \mathrm{Mn}, 0.019 \% \mathrm{Si}, 0.016 \% \mathrm{P}, 0.012 \% \mathrm{~S}$} \\
\hline
\end{tabular}


Table 3. Comparison of the effects of the stirring on crystal morphologies in continuously cast steel slabs and the $\mathrm{PbSn}$ alloy

\begin{tabular}{|c|c|c|c|c|c|}
\hline \multirow[b]{4}{*}{$\begin{array}{l}\text { Continuously } \\
\text { cast slab }\end{array}$} & \multicolumn{2}{|r|}{ Sample } & A & $\mathrm{B}$ & $\mathrm{C}$ \\
\hline & \multicolumn{2}{|c|}{ Casting speed (m/min) } & 0.7 & 1.0 & 1.3 \\
\hline & \multirow{2}{*}{$\begin{array}{l}\text { Conditions } \\
\text { of No. } 2 \\
\text { EMS }\end{array}$} & \multirow{2}{*}{$\begin{array}{l}\text { fc: liquid core ratio } \\
\text { fs : averaged solid fraction in } \\
\text { the liquid core (within the white } \\
\text { bands) }\end{array}$} & $0.07^{*}$ & $0.2^{*}$ & $0.37^{*}$ \\
\hline & & & $0.15^{* *}$ & $0.02^{* *}$ & $0.03^{* *}$ \\
\hline \multirow{4}{*}{$\begin{array}{l}\text { Analogue } \\
\text { study by } \mathrm{Pb}- \\
10 \% \mathrm{Sn} \text { alloy }\end{array}$} & \multicolumn{2}{|c|}{ Crystals observed in the liquid core } & $\begin{array}{c}\text { Coarse dendritic } \\
\text { crystals }\end{array}$ & $\begin{array}{l}\text { Refined } \\
\text { crystals }\end{array}$ & $\begin{array}{l}\text { Refined } \\
\text { crystals }\end{array}$ \\
\hline & & Sample & $\mathrm{K}$ & $\mathrm{D}$ & G \\
\hline & \multicolumn{2}{|c|}{ fs: solid fraction at which a mould was tumbled } & $0.4 \sim 0.7$ & $0.0 \sim 0.4$ & $0.0 \sim 0.5$ \\
\hline & \multicolumn{2}{|c|}{ Crystals typically observed in the samples } & $\begin{array}{c}\text { Coarse dendiric } \\
\text { crystals }\end{array}$ & $\begin{array}{l}\text { Refined } \\
\text { crystals }\end{array}$ & $\begin{array}{l}\text { Refined } \\
\text { crystals }\end{array}$ \\
\hline
\end{tabular}

(*) the ratio of the thickness of the unsolidified zone between the upper and bottom white bands relative to the slab thickness

(**) Estimated by the numerical heat analysis

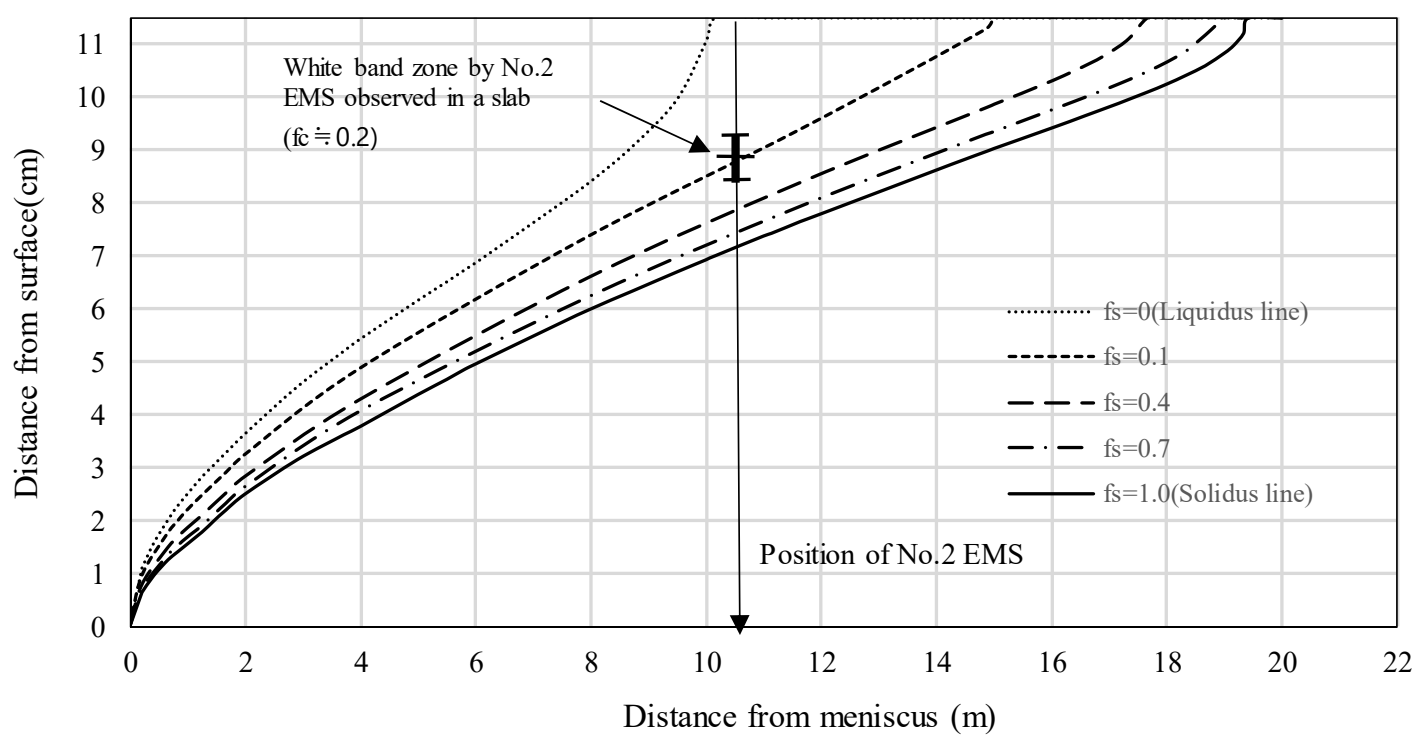

Figure 12. Development of shell thickness of the continuously cast steel slabs estimated by a numerical heat analysis (Mesh size of the thickness :0.00575cm, Mesh size of time:2.5x10-5 s, Casting speed: $1.0 \mathrm{~m} / \mathrm{min}$, Super heat in a mould $: 15 \mathrm{~K}$, Liquids temperature: $1798 \mathrm{~K}$,Solidus temperature: $1748 \mathrm{~K}$, Steel composition: $0.15 \% \mathrm{C}$, $0.65 \% \mathrm{Mn}, 0.019 \% \mathrm{Si}, 0.016 \% \mathrm{P}, 0.012 \% \mathrm{~S})$

\section{Conclusion}

The metallographic observations of the continuously cat steel slabs showed that the electro-magnetic stirring applied at low fraction solid refined crystals (globular crystals). The central region of the continuously cast steel with the optimum stirring was well packed with the refined crystals whereas it was not with coarse equiaxed crystals. The analogue study with experiments of $\mathrm{Pb}-\mathrm{Sn}$ alloy showed that the stirring at the low fraction solid was essential to refine crystals as found in the real process. It was also found the artificial cavity in a mush made during solidification was well packed with the refined, globular, crystals whereas it was not with the coarse dendritic crystals. Thus, hence, it is considered the stirring in the low fraction solid is important to refine crystals and improve macro-segregation in continuously cast steel slabs.

\section{Acknowledgements}

The authors express sincere appreciation to JFE steel (Kawasaki Steel) for support for the research.

\section{References}

Fujimura, T., \& Brimacombe, J. K. (1986). Mathematical Analysis of Solidification Behaviour of Multicomponent Alloys. Transactions of the Iron and Steel Institute of Japan, 26(6), 532-539. 
Fujimura, T., Takeshita, K., \& Suzuki, R. O. (2018). Mathematical Analysis of the Solidification Behavior of Plain Steel Based on Solute-and Heat-Transfer Equations in the Liquid-Solid Zone. Metallurgical and Materials Transactions B, 49(2), 644-657.

Fujimura, T., Takeuchi, E., \& Brimacombe, J. K. (1985). Segregation Phenomina in the Continuous Casting of Steel Slabs,Japan-Canada Seminar onSecondary Steelmaking (pp.C-5-1-15). The Iron and Steel Institute of Japan, Tokyo, Japan.

Fujimura, T., Yamasaki, H., Katano, T., \& Kajiwara, M. (1987). Effect of Elctro Magnetic Stirring on The Centerline Segregation of Continuously Cast Steel (pp.213-217). 70 ${ }^{\text {th }}$ Steelmaking conference, AIME.

Gouttebroze, S., Fachinotti, V. D., Bellet, M., \& Combeau, H. (2005). 3D-FEM modeling of macrosegregation in solidification of binary alloys. International Journal of Forming Processes, 8, pages-203.

Gryc, K., Smetana, B., Žaludová, M., Michalek, K., Klus, P., Tkadlečková, M., ... \& Pachlopnik, R. (2013). Determination of the solidus and liquidus temperatures of the real-steel grades with dynamic thermal-analysis methods. Mater.Technol., 47(2013), 569-575.

Haida, O., Kitaoka, H., Habu, Y., Kakihara, S., Bada, H., \& Shiraishi, S. (1984). Macro-and semi-macroscopic features of the centerline segregation in CC slabs and their effect on product quality. Transactions of the Iron and Steel Institute of Japan, 24(11), 891-898.

Hirai, M., Kanamaru, K., \& Mori, H. (1977). Tekko-no-Gyouko (Solidification of steel). By Solidification Comm., Joint Sc. on Iron and Steel Basic Research of ISIJ, ISIJ, Tokyo.

Kawawa, T. (1977). Tekko-no-Gyouko (Solidification of steel). Solidification Comm., Joint Sc. on Iron and Steel Basic Research of ISIJ, ISIJ, Tokyo.

Kitaoka, H., Fujimura, T., Nozaki, T., Habu, H., Kakihara, S., ... Tanigawa, H. (1983). Semimacroscopic Features of Centerline Segregation in CC slabs and Their Effects on Product Quality. Tetsu-to-Hagane, 69, A201.

Meng, Y. A., \& Thomas, B. G. (2003). Heat-transfer and solidification model of continuous slab casting: CON1D. Metallurgical and Materials Transactions B, 34(5), 685-705.

Ohashi, N. (1986). Effect on Ftracure Thoghnesee of steel. Tetsu-to-Hagane, 72, 747-757.

Saeki, T., Komai, T., Miyamura, K., Mizoguchi, S., \& Kajioka, H. (1985, April). Application of Spot Segregation Evaluating Methods in Continuously Cast Slab. In Steelmaking Proceedings, (Vol. 68, pp. 229-235).

Takahashi, T., Kudoh, M., \& Nagai, S. (1982). Estimation of Effective and Specific Permiability in the Mushy Zone of Steel Ingot by the Method of Seepage into Cylindrical Hole. Tetsu-to Hagane, 68, 623-632.

Ujiie, Y., Maede, H., Itoh, Y., Ogibayashi, S., Seki, H., Wada, K., \& Itoh, Y. (1981). Improving Solidification Structure of Continuously Cast Steel by Electromagnetic Stirring. Tetsu-to-Hagané, 67(8), 1297-1306.

Yamanaka, K. (1980). The Microstrucure and Thoghness of Steels Corresponding to the Chemical Composition of the Segregated Zone of the Plate. Tetsu-to-Hagane, 66, 1367-1373.

\section{Copyrights}

Copyright for this article is retained by the author(s), with first publication rights granted to the journal.

This is an open-access article distributed under the terms and conditions of the Creative Commons Attribution license (http://creativecommons.org/licenses/by/4.0/). 